LWSA

PAPER - OPEN ACCESS

\title{
Valuasi Ekonomi Hutan Sebagai Pengendali Banjir dan Erosi di Das Deli Berdasarkan Metode Kontingensi
}

\author{
Author : Nurdin Sulistiyono \\ DOI $\quad: 10.32734 /$ lwsa.v1i1.167 \\ Electronic ISSN : :2654-7058 \\ Print ISSN : 2654-7066
}

Volume 1 Issue 1 - 2018 TALENTA Conference Series: Local Wisdom, Social and Arts

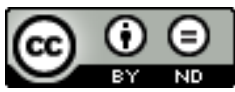

This work is licensed under a Creative Commons Attribution-NoDerivatives 4.0 International License.

Published under licence by TALENTA Publisher, Universitas Sumatera Utara
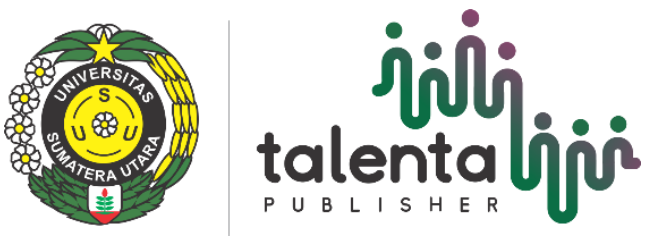


\title{
inj talenta ijọ TALENTA Conference Series \\ Available online at https://talentaconfseries.usu.ac.id
}

\section{Valuasi Ekonomi Hutan Sebagai Pengendali Banjir dan Erosi di Das Deli Berdasarkan Metode Kontingensi}

\author{
Nurdin Sulistiyono ${ }^{\mathrm{a}}$, Lamria Butarbutar ${ }^{\mathrm{a}}$, Pindi Patana ${ }^{\mathrm{a}}$ \\ "Program Studi Kehutanan, Fakultas Kehutanan, Universitas Sumatera Utara"
}

Email : nurdinsty2013@gmail.com

\begin{abstract}
Hutan memiliki banyak manfaat penyedia jasa lingkungan, diantaranya sebagai pencegah erosi dan banjir. Penelitian ini bertujuan untuk menghitung nilai ekonomi jasa lingkungan hutan sebagai pengendali banjir dan erosi berdasarkan metode kontingensi dan untuk mengetahui faktor-faktor yang mempengaruhi tingkat kesediaan membayar manfaat hutan sebagai pengendali banjir dan erosi di das Deli. Metode analisis yang digunakan adalah metode kontingensi dan biaya pencegahan sebagai nilai ekonomi hutan, analisis deskriptif dari data kuisioner, serta analisis regresi untuk mengetahui factor- faktor yang mempengaruhi tingkat kesediaan membayar manfaat hutan sebagai pengendali banjir dan erosi. Hasil penelitian menunjukkan nilai ekonomi hutan sebagai pengendali banjir dan erosi dengan metode kontingensi sebesar Rp. 153.314.076.583,33/tahun. Berdasarkan model regresi yang terbentuk dapat disimpulkan bahwa faktor yang mempengaruhi tingkat kesediaan membayar manfaat jasa lingkungan hutan sebagai pengendali banjir dan erosi di DAS Deli adalah tingkat pendapatan.
\end{abstract}

Kata Kunci: Valuasi ekonomi; kesediaan membayar; pengendali banjir; erosi, DAS

\section{PENDAHULUAN}

Hutan memiliki banyak manfaat berupa hasil hutan kayu, hasil hutan bukan kayu serta penyedia jasa lingkungan seperti pencegah banjir dan rosi. Keberadaan hutan di hulu DAS Deli sangat penting mengingat wilayah hilir DAS Deli merupakan daerah ibukota propinsi Sumatera Utara yaitu Kota Medan yang sangat kaya akan asset-asset nasional dan pemukiman penduduk. Namun, kondisi hutan di DAS Deli saat ini telah mengalami banyak perubahan dan sangat rentan terhadap kerusakan. Padahal pola penggunaan lahan di daerah hulu mempunyai eksternalitas negatif terhadap daerah hilir, misalnya dengan adanya dampak erosi dan banjir yang bisa terjadi di daerah hilir (Sulistiyono, 2006).

Banjir merupakan permasalahan umum yang terjadi di sebagian wilayah Indonesia, termasuk di daerah padat penduduk misalnya di kawasan perkotaan. Oleh karena itu kerugian yang ditimbulkannya besar baik dari segi materi maupun kerugian jiwa, maka sudah selayaknya permasalahan banjir perlu mendapatkan perhatian yang serius dan merupakan permasalahan kita semua (Kodoatie et al., 2002). Penanganan masalah banjir dan erosi tidak bisa dilepaskan dari keberadaan hutan di daerah hulu beserta aktivitas masyarakatnya. Salah satu hal yang cukup penting untuk meningkatkan kesadaran masyarakat adalah dengan cara memberikan informasi mengenai besarnya nilai ekonomi jasa lingkungan hutan sebagai pengendali banjir dan erosi. Namun demikian nilai-nilai jasa lingkungan ini sering tidak terefleksi dalam harga pasar (Bishop, 1999).

Belum adanya informasi nilai ekonomi mengenai jasa lingkungan hutan di DAS Deli, maka perlu adanya penelitian mengenai nilai ekonomi jasa lingkungan hutan di DAS Deli khususnya sebagai pengendali banjir dan erosi. Penelitian ini bertujuan menghitung nilai ekonomi jasa lingkungan hutan sebagai pengendali banjir dan erosi di DAS 
Deli berdasarkan metode kontingensi serta menentukan faktor-faktor yang mempengaruhi kesediaan membayar manfaat hutan sebagai pengendali banjir dan erosi di DAS Deli

\section{METODE PENELITIAN}

\subsection{Waktu dan Tempat Penelitian}

Penelitian dilakukan di DAS Deli meliputi empat wilayah yaitu Desa Doulu, Kabupaten Karo; Desa Sikeben dan Desa Sibiru-biru, Kabupaten Deli Serdang Belawan Bahari, Kota Madya Medan. Penelitian dilakukan pada bulan April sampai September 2009.

\subsection{Populasi dan Sampel}

Penarikan sampel dilakukan dengan metode purposive sampling dengan tetap mempertimbangkan ketersebaran dan keterwakilan responden yang diambil. Unit sampel yang digunakan dalam penelitian ini adalah rumah tangga. Sampel diperoleh dari empat desa yang terletak di DAS Deli bagian hulu, tengah dan hilir. Lokasi penelitian bagian hulu yaitu Desa Doulu, bagian tengah Desa Sikeben dan Desa Biru-biru serta bagian hilir yaitu Kelurahan Labuhan Deli, Kecamatan Medan Marelan. Unit sampel yang diambil dari keempat lokasi penelitian ini berjumlah 80 responden. Populasi penelitian adalah seluruh rumah tangga yang berada di dalam daerah aliran sungai Deli mulai dari hulu, tengah, hilir. Jumlah populasi rumah tangga di DAS Deli diperkirakan berjumlah 384.905 rumah tangga (BPS, 2008).

\subsection{Pengolahan Data}

Penentuan nilai ekonomi hutan sebagai pengendali banjir dan erosi dilakukan dengan menggunakan metode kontingensi yakni dengan menanyakan besarnya kesediaan membayar atau Willingness to Pay (WTP) dari responden untuk menjaga hutan agar bisa menjalankan fungsinya sebagai pengendali banjir dan erosi. Metodologi penelitian kontingensi mengacu pada penelitian Adams et al. (2008); Gürlük (2006); Amirnejad et al. (2006); Jim and Chen (2009). Pengumpulan data WTP di lapangan berdasarkan penyebaran kuisioner kepada responden. Penyebaran kuisioner menggunakan alat bantu gambar sebagai media cetak yang dapat memberikan penjelasan dan gambaran mengenai manfaat hutan sebagai pengendali banjir sehingga diharapkan responden dapat memberikan nilai kesediaan membayar yang lebih realistis. Selain penyebaran kuisioner, melakukan wawancara (interview). Formula (1) dan (2) berikut digunakan untuk menghitung besarnya WTPresponden terhadap nilai ekonomi jasa lingkungan hutan sebagai pencegah banjir dan erosi.

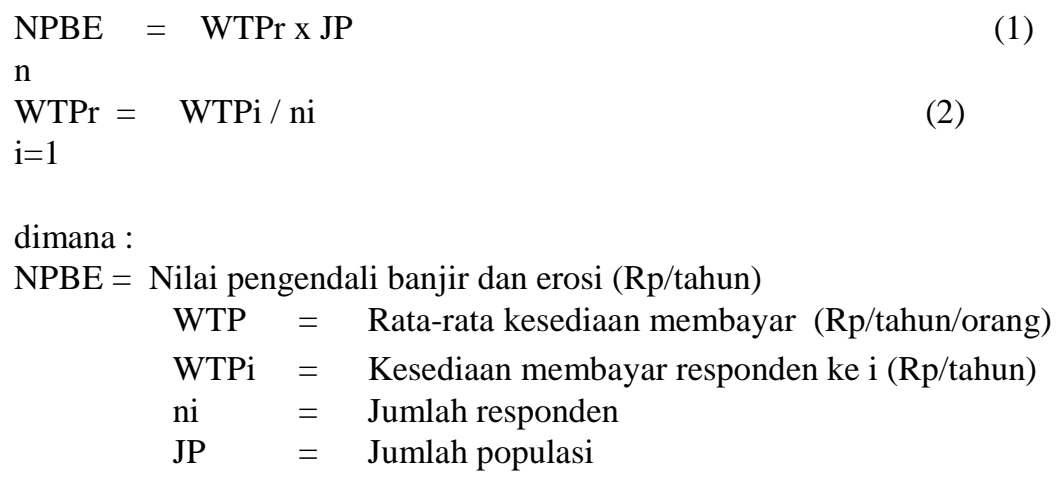

Besarnya nilai WTP yang diberikan responden dipengaruhi oleh banyak faktor. Untuk mengetahui fakor-faktor yang berpengaruh terhadap WTP digunakan analisis regresi dengan metode stepwise menggunakan SPSS. Model persamaan regresi yang dipakai mengikuti persamaan (3). 


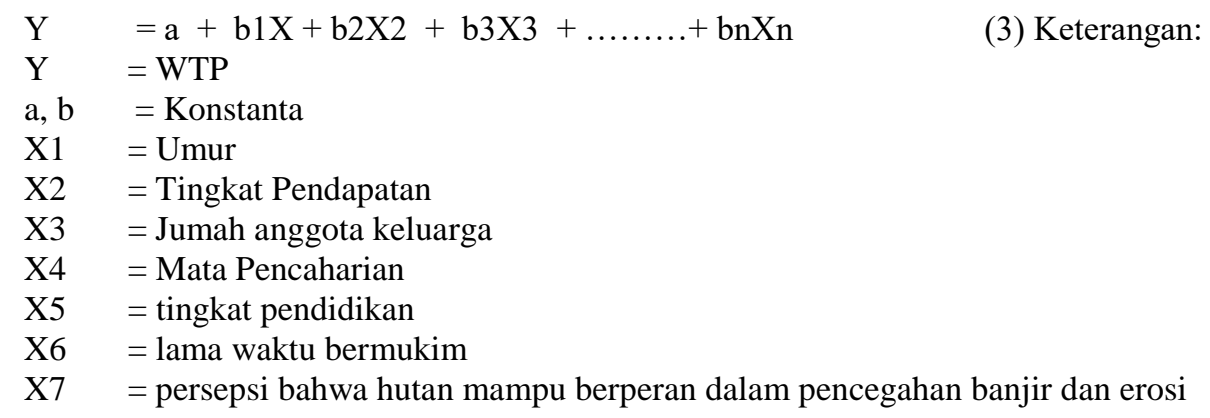

Untuk mengetahui besarnya biaya yang dikorbankan oleh masyarakat didekati dengan menggunakan besarnya biaya pencegahan, dengan asumsi besarnya biaya yang dikorbankan oleh masyarakat sama dengan besarnya biaya pencegahan yang dikeluarkan untuk menanggulangi banjir dan erosi di DAS Deli. Biaya Pencegahan dapat diperoleh dari biaya-biaya yang dikeluarkan oleh instansi yang bersangkutan seperti Balai Pengelolaan Aliran Sungai Wampu dan Dinas Kehutanan Kabupaten dalam kegiatan Gerakan Rehabilitasi Hutan dan lahan (Gerhan) serta Departemen Pekerjaan Umum dalam kegiatan pembangunan kanal untuk pengendalian banjir di DAS Deli bagian hilir.

\section{HASIL DAN PEMBAHASAN}

\subsection{Nilai Ekonomi Hutan sebagai Pengendali Banjir dan Erosi}

Hasil penelitian menunjukan besarnya kesediaan membayar masyarakat untuk membayar agar hutan di DAS Deli tetap terjaga dengan baik sehingga fungsi sebagai pengendali banjir dan erosi dapat berfungsi dengan optimal adalah Rp.398.316,67/orang/tahun. Jika digandakan dengan seluruh jumlah rumah tangga yang ada di DAS Deli sebesar 384.905 KK, maka besarnya nilai ekonomi hutan sebagai pengendali banjir dan erosi di DAS Deli sebesar Rp. 153.314.076.583,33/tahun. Hasil penelitian ini masih lebih tinggi jika dibandingkan penelitian Adams et al. (2008) yang menyebutkan nilai kesediaan masyarakat untuk biaya konservasi hutan di Morro do Diabo State Park, Brazil sebesar US\$2,113,548.00/tahun, perbedaan nilai sangat dipengaruhi oleh jumlah populasi masyarakat.

\subsection{Besarnya biaya Pencegahan Banjir dan Erosi}

Besarnya biaya pengendalian banjir dan erosi secara struktur yang dikeluarkan oleh pemerintah kota Medan dengan membangun kanal di Sungai Deli adalah Rp 727.896.854.487. Biaya tersebut ditujukan untuk pembangunan kanal dengan masa pakai diperkirakan selama 50 tahun. Sehingga biaya yang dikeluarkan pemerintah untuk pengendalian banjir dan erosi secara struktur di DAS Deli setiap tahun berkisar Rp 14.559.937.088/tahun. Perincian Biaya Pengendalian secara struktur dalam Pembangunan Kanal di DAS Deli bagian hilir dapat dilihat pada Tabel 1.

Perincian biaya pengendalian banjir dan erosi secara struktur pembangunan kanal di DAS Deli bagian hilir

\begin{tabular}{clcc}
\hline No & Komponen & Tahun & Biaya (Rp) \\
\hline 1 & Biaya Konsultan & & $36.972 .227 .492,00$ \\
2 & Tahap 1 & 2006 & $41.380 .081 .049,84$ \\
3 & Tahap 2 & 2006 & $74.713 .816 .406,86$
\end{tabular}




$\begin{array}{rlrr}4 & \text { Tahap 3 } & 2007 & 91.923 .853 .267,00 \\ 5 & \text { Tahap 4 } & 2007 & 78.228 .133 .205,00 \\ 6 & \text { Tahap 5 } & 2008 & 137.170 .740 .548,00 \\ 7 & \text { Tahap 6 } & 2008 & 141.330 .837 .721,30 \\ 8 & \text { Tahap 7 } & 2008 & 110.291 .870 .671,00 \\ 9 & \text { Tahap 8 } & 2008 & 16.185 .294 .124,49 \\ & \text { Total Biaya } & & 727.896 .854 .487,00 \\ & \text { Total Biaya per Tahun } & 14.559 .937 .089,79\end{array}$

Sumber: $\quad$ Departemen Pekerjaan Umum, Kegiatan Pengendalian Banjir dan Perbaikan Sungai II (2009)

Selain biaya pengendalian banjir secara struktur, pemerintah juga mengeluarkan biaya pengendalian banjir dan erosi di DAS Deli secara non struktur berupa gerakan rehabilitasi hutan dan lahan (Gerhan) yang berlokasi di Kabupaten Deli Serdang. Kegiatan Gerhan yang dilakukan dibagi menjadi 2 yaitu secara vegetasi dan silviteknis. Metode vegetasi yang digunakan adalah hutan rakyat (HR), reboisasi (R), hutan rakyat insentif (HRI), hutan rakyat pengkayaan (HRP) dan hutan kota (HK). Sedangkan metode silviteknis dengan cara membuat sumur resapan (SR), penahan sistem bronjong (PSB) dan embung air (EA). Besarnya biaya pengendalian banjir dan erosi yang dikeluarkan pemerintah untuk kegiatan tersebut adalah $\mathrm{Rp} 2.357 .820 .600,00 /$ thn dengan luas areal 977 ha dari 10.794 ha areal yang masuk dalam program Gerhan. Perincian biaya pengendalian banjir secara non struktur dapat dilihat pada Tabel 2.

Tabel 2. Perincian biaya pengendali banjir dan erosi secara non struktur di Kabupaten Deli Serdang

\begin{tabular}{lrlr}
\hline Kecamatan & Luas (Ha) & \multicolumn{1}{c}{ Kegiatan } & \multicolumn{1}{c}{ Rp/thn } \\
\hline Kec. Sibolangit & 623 & HR, HRP, R, HRI, HK, SR, EA, PSB & 1.705 .265 .000 \\
Kec. & 52 & HR, PSB & 140.005 .600 \\
$\begin{array}{l}\text { Namorambe } \\
\text { Kec. }\end{array}$ & 302 & HRP, R, EA & 512.550 .000 \\
$\begin{array}{l}\text { Kutalimbaru } \\
\text { Total }\end{array}$ & & & \\
\hline
\end{tabular}

Sumber: Dinas Kehutanan Kabupaten Deli Serdang (2004-2007)

Total biaya pengendalian banjir dan erosi yang telah dikeluarkan oleh pemerintah secara struktur dan non struktur di DAS Deli sampai saat ini sebesar Rp 16.917.757.688,00/thn. Jika seluruh areal dalam program Gerhan di DAS Deli telah dilakukan maka diperkirakan total biaya yang akan dikeluarkan oleh pemerintah untuk pengendalian banjir dan erosi di DAS Deli sebesar Rp.40.609.390.063,00/thn. Perbedaan nilai ekonomi tersebut dapat dilihat pada Gambar 1. 


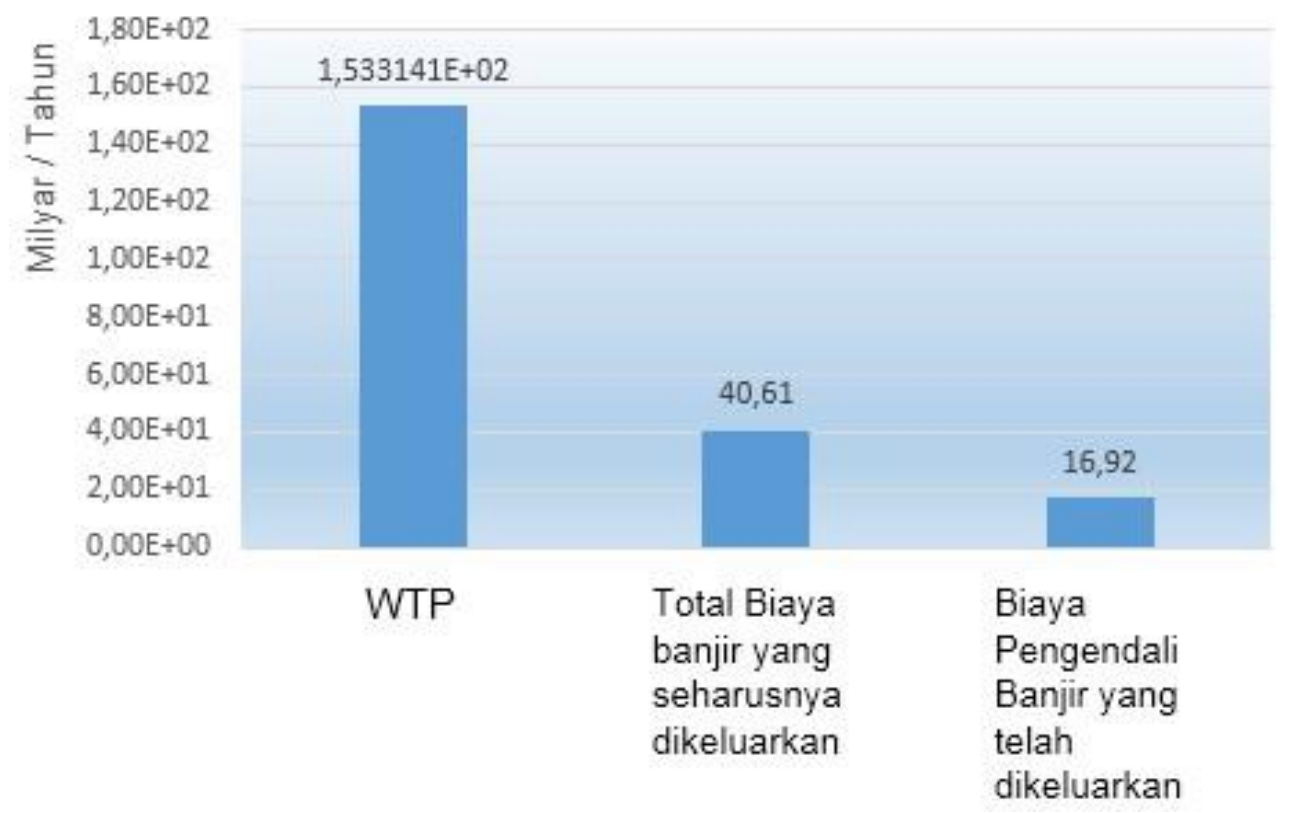

Gambar 1. Perbandingan Nilai Ekonomi Hutan Berdasarkan Willingness to Pay dengan Biaya Pengendali Banjir

Jika dengan asumsi besarnya nilai yang dikorbankan sama dengan total biaya pengendalian banjir dan erosi di DAS Deli yang seharusnya oleh pemerintah kota Medan yaitu sebesar Rp 40.609.390.063,00, maka tingkat kepuasaan masyarakat atau surplus bagi konsumen yang didapat sebesar Rp 112.704.686.520,33. Dalam hal ini besarnya nilai yang dikorbankan jauh lebih kecil dari manfaat atau tingkat kepuasan masyarakat yang diperoleh dalam bentuk surplus konsumen. Dengan mengorbankan biaya sebesar Rp 40.609.390.063,00/thn maka masyarakat akan memperoleh kepuasan atau surplus konsumen sebesar Rp. 112.704.686.520,33. Hal ini disebabkan karena manfaat jasa hutan sebagai pencegah banjir dan erosi merupakan manfaat hutan yang bersifat intangible yang dipandang sebagai barang public (public goods).

Sesuai dengan pernyataan Suyana (2009) hutan sebagai penyedia jasa lingkungan seperti rekreasi, fungsi hidrologi, dan habitat flora dan fauna dipandang sebagai public goods atau common property resources sebagai sumber daya milik bersama, maka prinsipnya siapa cepat dia yang dapat menjadi

kaidah umum dalam pemanfaatan sumberdaya tersebut. Setiap individu masyarakat akan berlomba- lomba untuk sedapat mungkin memperoleh hasil sebanyak-banyaknya dalam waktu yang singkat tanpa memperdulikan kebutuhan bersama atau kelestarian sumberdaya milik bersama tersebut.

Ciri umum sumberdaya yang bersifat public goods adalah lemahnya tingkat proteksi oleh masing- masing individu terhadap sumberdaya tersebut. Walaupun sumberdaya alam tersebut bersifat renewable, dapat dipastikan kehancurannya akan sangat mudah, karena setiap orang hanya berfikir bagaimana mengambil sumberdaya alam milik bersama sebanyak-banyaknya dalam waktu singkat. Secara individual, masyarakat tidak akan tergolong/tidak ada insentif untuk menjaga dengan baik keberadaan hutan. Hal ini akan berbeda dengan barang yang bersifat personal right, dimana setiap individu akan mempertahankan dengan segenap kemampuannya untuk menjaga dan mempertahankan apa yang menjadi miliknya.

Disamping itu, produk hutan sebagai fungsi hidrologis (Pencegah banjir) yang jika dikonsumsi oleh seseorang tidak mempengaruhi/mengurangi jumlah yang didapat oleh orang yang lainnya karena merupakan milik bersama dan tersedia dalam jumlah yang melimpah. Sehingga masyarakat dengan sesuka hatinya dapat merasakan manfaat hutan tersebut. Selain itu juga barang publik bersifat under pricing yaitu tidak masuknya public goods ke dalam market system membuat masyarakat sebagai individu dan kelompok sulit di dalam menentukan harga dari public goods. Sementara harga juga sesungguhnya mencerminkan nilai relatif suatu sumberdaya terhadap sumberdaya lainnya. 


\section{Faktor-Faktor yang Mempengarui WTP}

Berdasarkan analisis regresi dengan metode stepwise diketahui bahwa kesediaan membayar jasa hutan sebagai pencegah banjir dan erosi di DAS Deli hanya dipengaruhi oleh faktor pendapatan (X2). Model penduga kesediaan membayar jasa hutan sebagai pencegah banjir dan erosi yang dihasilkan dalam penelitian ini adalah $\mathrm{Y}=-182.686,8+$ 0,446 X2 dengan R2 sebesar 60,3\%. Koefisien regresi sebesar 0,446 pada variabel pendapatan menyatakan bahwa setiap peningkatan tingkat pendapatan satu satuan akan meningkatan nilai kesediaan membayar manfaat hutan sebagai pencegah banjir sebesar Rp 0,446. Tingkat pendapatan masyarakat akan sangat menentukan besarnya kemampuan seseorang dalam memenuhi tingkat kebutuhannya. Semakin besar tingkat pendapatan maka kemampuan untuk memenuhi kebutuhan hidupnya semakin besar. Hal ini juga berdampak pada WTP masyarakat dalam penelitian ini dimana semakin besar tingkat pendapatan maka semakin besar juga nilai WTP masyarakat untuk membayar jasa hutan sebagai pencegah banjir dan erosi. Example of a sub-heading within an appendix

\section{KESIMPULAN}

1. Nilai ekonomi jasa lingkungan hutan sebagai pengendali banjir dan erosi berdasarkan metode kontingensi adalah Rp. 153.314.076.583,33/tahun.

2. Faktor pendapatan merupakan faktor yang mempengaruhi tingkat kesediaan membayar jasa lingkungan hutan sebagai pengendali banjir dan erosi di DAS Deli.

\section{DAFTAR PUSTAKA}

[1] Adams, C., da Motta , R.S., Ortiz, R.A., Reid, J., Aznar, C.E., Sinisgalli, P.A. (2008). The use of contingent valuation for evaluating protected areas in the developing world: Economic valuation of Morro do Diabo State Park, Atlantic Rainforest, São Paulo State (Brazil). Ecological Economics 66 (2-3), 359-370. doi.org/10.1016/j.ecolecon.2007.09.008.

[2] Amirnejad, H., Khalilian, S., Assareh, M.H., Ahmadian, M. (2006). Estimating the existence value of north forests of Iran by using a contingent valuation method, Ecological Economics 58 (4), 665-675. doi.org/10.1016/j.ecolecon.2005.08.015.

[3] Bishop JT. (1999). Valuing Forests : A Review of Methods and Applications in Developing Countries. London: International Institute for Environment and Development.

[4] [BPS] Badan Pusat Statistik. (2008). Sumatera Utara Dalam Angka. BPS Provinsi Sumatera Utara. Medan

[5] [DPU] Departemen Pekerjaan Umum. (2009). Kegiatan Pengendalian Banjir dan Perbaikan Sungai II. Medan.

[6] Gürlük, S. (2006). The estimation of ecosystem services' value in the region of Misi Rural Development Project: Results from a contingent valuation survey. Forest Policy and Economics 9 (3), 209-218. doi.org/10.1016/j.forpol.2005.07.007. 